\title{
Construction and Practice of Integrated Innovation Training Platform Based on Converged Network
}

\section{Wu Yu}

Department of Communication and Information Engineering, Century College, Beijing University of Posts and Telecommunications, Beijing, China

\section{Email address: \\ wuyuq2003@163.com}

\section{To cite this article:}

$\mathrm{Wu}$ Yu. Construction and Practice of Integrated Innovation Training Platform Based on Converged Network. Science Discovery.

Vol. 4, No. 5, 2016, pp. 315-319. doi: 10.11648/j.sd.20160405.20

Received: September 29, 2016; Accepted: October 17, 2016; Published: October 19, 2016

\begin{abstract}
Combined with Beijing (the capital of China) private education development promotion project-triple play integrated innovation training base construction of Century College, Beijing University of Posts and Telecommunications, the method of implemetation of training platform construction based on converged network is introduced. Based on the training platform, the three network service integration of telecommunications, broadcasting and data has been developed, and the training teaching method has been explored in researching and practicing, so that the communication training environment of college and the comprehensive abilities of students are both improved, as well as the effect is remarkable.
\end{abstract}

Keywords: Converged Network, Integrated Innovation, Training Platform

\section{基于网络融合的综合创新实训平台构建与实践}

吴娱

通信与信息工程系, 北京邮电大学世纪学院, 北京, 中国

邮箱

wuyuq2003@163. com

摘要：结合中国北京民办教育发展促进项目一北京邮电大学世纪学院三网融合综合创新实训基地建设,介绍了基于网络 融合的实训平台构建的实现方式。基于该实训平台, 开展了电信、广电、数据三网相关业务的融合, 对实训教学方式 进行了研究与实践的探索, 改善了学院通信实训环境, 全面提高了学生的综合应用能力, 效果显著。

关键词：网络融合, 综合创新, 实训平台

\section{1. 引言}

2001年的中华人民共和国国民经济和社会发展第十个 五年计划纲要中提出的三网融合概念, 即电信网、广电网、 计算机网络的相互融合, 通过网络融合来促进互联互通各 项业务的融合，对促进国家信息化建设有重要的意义 [1]。 随着国家对网络融合的推进，在现代信息化教育中，各大
高校顺应时代发展趋势, 建设基于网络融合的电信和广电 工程实训平台 $[2]$ 。本文结合北京邮电大学世纪学院依托 的中国北京民办教育发展促进项目, 构建三网融合综合创 新实训平台, 探讨基于网络融合的业务平台和实训项目。 


\section{2. 综合创新实训平台的构建}

北京邮电大学世纪学院构建基于网络融合的综合创 新实训平台, 涵盖了三网融合的主要节点, 采用先进的PTN

（分组传送网, Packet Transport Network）传输承载技 术和PON（无源光网络, Passive Optical Network）接入 技术, 将电信、广电、数据同时接入, 实现IPTV (网络电 视, Internet Protocol Television) 和VoIP (网络电话, Voice over Internet Protocol) 业务。整个系统中的每 个设备可以独立运行, 也可以通过承载网络与其他设备组
成网络 $[3,4]$ 共同运行。该实训平台构建的系统拓扑图如 图1所示。

\section{1. 前端信号源部分}

综合创新实训平台前端信号源部分包括卫星接收天 线、卫星电视信号接收机、地面波接收机、有线电视机顶 盒、编解码器、信号监控设备等。

此部分主要是将卫星电视、有线电视、地面波等不同 形式的信号, 通过复用、调制、加扰等手段进行处理后解

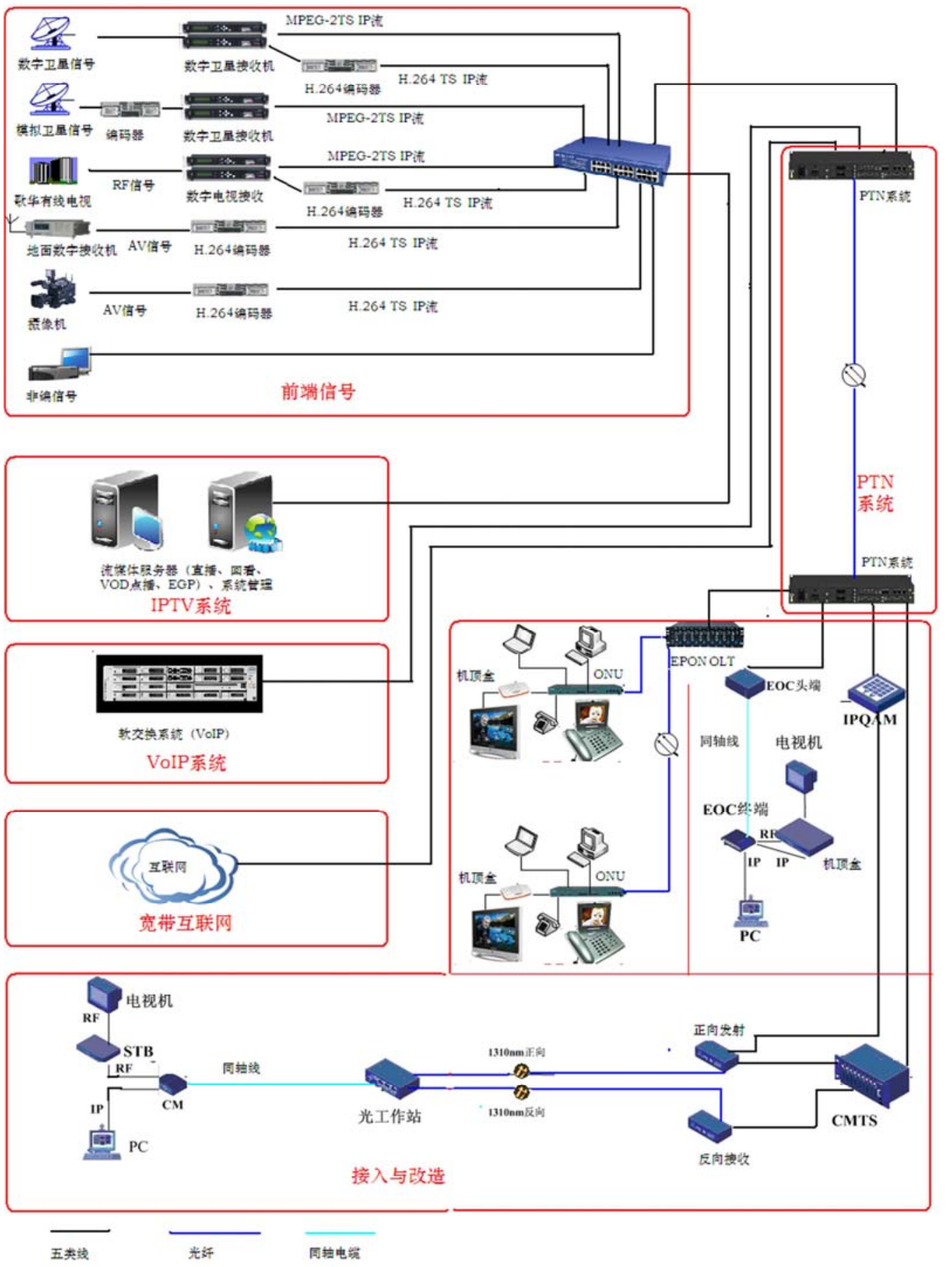

图1 综合创新实训平台系统拓扑图。 
码出视频信号和音频信号, 然后通过编码器对这些信息进 行编码, 将前端不同形式的信号变换成符合H. 264标准TS IP码流形式, 存储到IPTV系统中, 这样就能实现电视的直 播、点播等多种业务。

\section{2. 业务提供服务器}

综合创新实训平台通过软交换系统提供电话业务、 IPTV服务系统提供电视业务, 通过PTN传输承载网进行光 纤传输, 通过EPON接入网将信号输送到用户, 在用户侧按 需进行解码到各个家庭设备, 从而实现真正意义上的三网 融合。

\section{3. 干线部分}

综合创新实训平台的干线部分, 也叫传输系统, 负责 信号的远距离传输。该平台采用光纤进行传输, 传输距离 可达 20-30km, 当距离超过这个距离的时候, 使用中继器 对光信号进行放大, 就可以传输更远的距离。在实验室构 建的该综合创新实训平台模拟现实传输系统, 两端采用 PTN设备, 中间采用光缆, 组成简单的传输系统。

\section{4. 接入部分}

综合创新实训平台的接入部分采用的是EPON实现宽 带接入, 组网形式灵活, 选用EPON+LAN、EPON+FTTH、 EPON+EOC等多种形式, 可提供语音、数据、视频、CATV 等多种业务 [5]。

EPON+FTTH (光纤到户, Fiber To The Home) 组网形式 如图2所示。一台OLT设备可以配置多个PON, 而每个PON 口通过分光器 (1：16或者 $1: 32)$, 可以配置1-16或1-32 个 $\mathrm{ONU}$ 设备, 从而实现光纤到户。

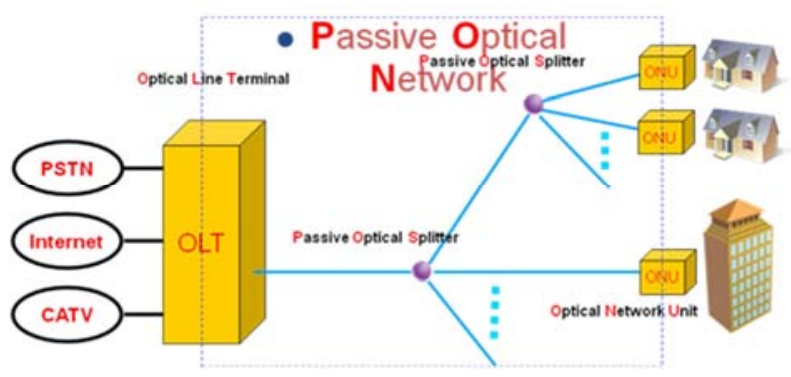

图2 接入网EPON+FTTH组网形式。

\section{5. 用户部分}

综合创新实训平台的用户侧使用的是ONU设备, 进行 光纤中携带的IP数据、电视、电话三种业务的分离, 分别 还原成IP数据信号、电视信号和电话信号。

\section{3. 基于网络融合的综合业务平台}

\section{1. IPTV}

IPTV是交互式网络电视, 基于宽带有线电视网集成多 媒体、互联网及通讯技术为用户提供多种交互式服务的一
种新技术 [6]。用户可通过计算机、网络机顶盒与普通电 视、移动设备三种方式获得相关服务。IPTV可对网络资源 进行充分利用, 可实现多播流转发、点播、基于Web的编 解码、实时传输等业务。

\section{2. VoIP}

VoIP即网络电话, 是综合创新实训的语音业务平台。 该平台由四种类型的设备部件组成: 控制部件、网关部件、 终端部件和管理部件 [7]。

控制部件就是软交换系统, 完成呼叫控制功能, 是系 统的核心部件 [8]。该平台所使用的软交换系统是GICS-I 型综合实验系统, 由软交换网络的核心设备和终端组成, 其拓扑连接如图3所示。

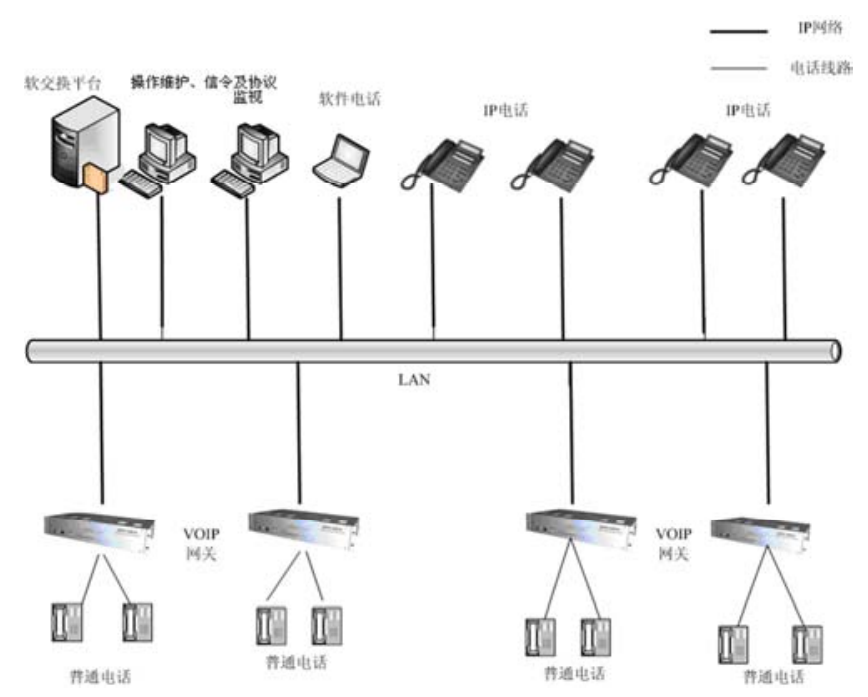

图3 GICS-I型软交换综合实验系统拓扑连接图。

网关部件就是VoIP网关, 其功能是终接电话机, 完成 媒体和信令转换。

终端部件包含三种终端: IP网络电话机、IP软件电话、 模拟电话机。其中, IP网络电话机采用配套的标准SIP话 机, IP软件电话就是在PC机上开发的SIP电话终端, 模拟 电话机和VoIP网关组合构成等效的IP网络电话。所有终端 在软交换系统的控制下进行电话呼叫通信。呼叫控制采用 SIP协议, 数字话音信号采用RTP协议封装后作为IP数据包 在网络中传递。

管理部件包括操作维护台和监视台。操作维护台的功 能是对软交换系统进行配置管理, 同时也作为计费管理平 台使用。监视台的功能是监视系统运行过程中的所有协议 消息, 包括SIP信令协议消息、RTP数据包和其他任何需要 观察的协议报文。

\section{4. 综合创新实训项目的实践}

根据学生培养目标, 该综合创新实训平台所开设项目 内容分为专业基础型和综合创新型。下面列举实训平台上 开设的主要实训内容。 


\section{1. 专业基础实训项目}

(1) 系统设备认知、网络参数配置

系统设备认知和网络参数配置部分主要让学生掌 握系统的拓扑结构, 了解组网规则和网络设置, 了解设 备在系统中的作用和特点及各接口功能, 保证设备正常 工作。包括平台设备的安装、调试和设备的基础配置, 系统组网、接口配置、系统维护管理等。

下面以卫星数字电视接收设备的安装与调试实训项 目为例, 列举实训中的重点环节。

A. 实训目的: 熟悉卫星接收天线主要技术参数; 掌握 天线的安装调试方法; 熟悉高频头的作用, 掌握高频头的 选用; 熟悉卫星数字电视接收机组成及其工作原理; 掌握 卫星数字电视接收机的使用方法。

B. 实训内容: 天线的安装与调试; 卫星数字电视接收 机的使用与调试。

该平台使用四进四出DVB-S接收机，具有高集成度、 高性价比的接收机。该设备的最大特点在于它将四个功能 独立的DVB-S接收机集成于一个标准 $1 \mathrm{U}$ 箱内, 每个卫星接 收机均有各自的复合视频、音频、ASI输入和ASI输出, 可 独立工作, 互不影响。这种模板设计极大地实现了功能和 结构的优化, 大大节约了设备运输成本, 机架空间和功能 消耗, 为用户提供了更加方便的操作体验。

其中, 卫星数字电视接收机线缆连接图如图4所示。

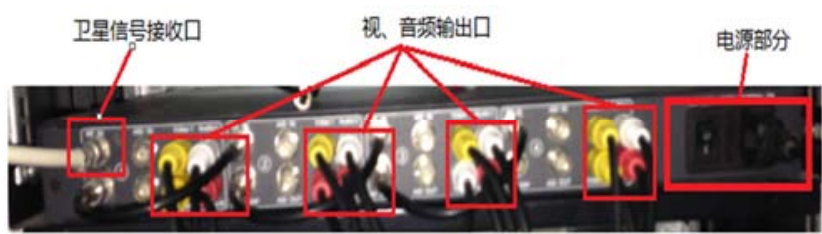

图4 卫星数字电视接收机线缆连接图。

(2) 传输与接入平台的操作

传输与接入平台实训项目包括光纤传输线路工程、设 备接口配置、系统测试及优化、组网配置、维护管理、线 缆制作、宽带接入设备连接、环境配置等。

传输系统部分实训项目如表1所示。

表1 传输系统部分实训项目

\begin{tabular}{ll}
\hline 实训1 & PTN设备的安装 \\
实训2 & PTN设备基本配置与网管平台基本操作 \\
实训 3 & PTN网络拓扑及网元配置实验 \\
实训4 & 传输业务配置实验 \\
实训 5 & 告警维护 \\
\hline
\end{tabular}

接入系统部分实训项目如表2所示。

表2 接入系统部分实训项目。

\begin{tabular}{ll}
\hline 实训 1 & EPON网络规划 \\
实训 2 & OLT硬件结构 \\
实训 3 & OLT设备安装 \\
实训 4 & ONU设备安装与配置 \\
实训 5 & ODF安装技术 \\
实训6 & EPON网管系统的安装与操作 \\
实训 7 & VLAN 配置 \\
实训 8 & 组播业务配置 \\
\hline
\end{tabular}

\begin{tabular}{ll}
\hline 实训 9 & VOIP业务配置 \\
实训10 & CES业务配置 \\
实训11 & 安全管理配置 \\
实训12 & QOS配置 \\
实训 13 & 生成树配置 \\
实训14 & 上联保护配置 \\
实训 15 & EOC用户端硬件安装 \\
实训 16 & EOC局端安装与数据配置 \\
\hline
\end{tabular}

（3）局内基本语音业务实现

基于软交换系统的语音业务实训包括对局内VoIP网 络进行规划并分配IP地址、系统搭建、设备连接、SIP呼 叫原理及故障诊断等。在软交换系统中配置好开局电话号 码, 对普通电话机和IP电话机进行注册, 通过互相拨打验 证实训结果的正确性。

语音业务部分实训项目如表3所示。

表3 语音业务部分实训项目。

\begin{tabular}{ll}
\hline 实训 1 & 软交换系统配置实验 \\
实训 2 & IP电话终端注册实验 \\
实训 3 & IP电话基本呼叫实验 \\
实训 4 & IP电话和模拟电话互通实验 \\
实训 5 & IP电话补充业务实验 \\
实训6 & SIP信令跟踪实验 \\
实训 7 & RTP信令跟踪实验 \\
实训 8 & 软交换系统组网实验 \\
\hline
\end{tabular}

（4）局内基本视频业务实现

数字电视平台和 IPTV系统实训项目主要包括数字电 视系统调试、IPTV服务器配置, 维护管理等。要求学生完 成电视系统测试、IPTV服务器用户管理、直播电视和点播 电视节目的配置和推送到终端, 通过机顶盒接收, 从用户 电视机上能够实现视频业务。

视频业务部分实训项目如表4所示。

表4 视频业务部分实训项目。

\begin{tabular}{ll}
\hline 实训1 & 地址网络规划 \\
实训2 & 服务器安装 \\
实训 3 & IPTV系统用户管理 \\
实训4 & IPTV系统直播栏目和频道配置 \\
实训 5 & IPTV系统直播频道节目单 \\
实训6 & IPTV系统上传和下载 \\
实训7 & IPTV系统点播栏目和频道配置 \\
实训 8 & IPTV系统走马灯配置 \\
\hline
\end{tabular}

\section{2. 综合创新实训项目}

依托通信与信息工程系各实验平台的背景, 该平台基 于网络的融合, 开设的综合创新实训项目涵盖电信和广电 系统工程设计项目 [9], 主要包括数字有线电视网络组网 设计、IPTV系统组网设计与平台设计、数字电视系统测试 及故障分析、数字电视机顶盒EPG设计与实现、VoIP系统 设计与调测、软件电话SIPPHONE开发等 [10]。

这类项目以综合创新为导向，采用启发式、自主式、 研究式教学方式, 并结合多媒体技术、网络技术等多种教 学手段, 以项目驱动方式激发学生的自主学习意识, 培养 学生的综合创新实践能力、自主学习和科研能力。 


\section{5. 实训教学方式的研究与探索}

基于网络融合的综合创新实训平台是一个整网在线 运行的平台, 与单一业务单一平台相比, 系统性和综合性 更强。在实训教学方式上做了如下研究和探索。

\section{1. 教学方式的改进}

按照实训内容分为专业基础实训项目和综合创新实 训项目, 采用灵活的教学方式。对于专业基础验证性实训 项目, 要保证每个学生都通过对设备的安装、调试及数据 配置等, 观察结果, 将理论知识和实践相结合。对于综合 创新实训项目, 通过教师指导, 自行查阅相关文献资料, 按要求进行方案设计, 在创新平台上进行演示验证, 提高 学生的自主学习能力。

另外，该平台提供开放的接口，既可以为教师提供科 研平台, 又可以鼓励部分有能力的学生参加科研课题的研 究, 同时为学生参加各项通信类大赛提供环境支持和保证, 从而为培养学生的实践创新思维能力奠定良好的基础。

\section{2. 考核方式的探索}

该综合创新实训平台的建立促进教师对考核方式进 一步探索。除基础性实训项目采取常规考核方式（实训成 绩+实训报告成绩=总成绩）外, 综合创新和开放性项目均 采用多元化的量化方法, 量化参数包括设计思路是否合理、 方案是否规范、技术是否可行、在平台上的演示效果如何、 报告质量等, 并且最终需要答辩进行考核评定。改进的这 种考核方式不仅可以增强学生自主学习的积极性, 养成良 好的阅读文献资料和编写文档的能力, 培养团队协作能力, 提高责任性, 更重要的是通过答辩环节, 能够正确认识不 足, 并进一步提出改进的思路。

\section{6. 结论}

基于网络融合的综合创新实训平台以目前广电和电 信运营商的实际组网方式为出发点, 初步建成了集数字有 线电视平台、IPTV系统平台、软交换平台、PTN传输平台、 宽带接入平台于一体的整网在线运行的实训平台, 可实现 IP数据、电视、电话三种业务的接入, 目前已成为通信与 信息工程系各专业学生的校内实习实训基地。学生在校内 就可完成对广电和电信工程的规划、设计, 对设备的安装、 调试, 模拟企业实际运行完成对系统的测试和故障分析, 进一步巩固和深化所学到的理论知识, 提高发现问题、分 析问题和解决问题的能力。
该平台在为学生提供现场实训环境的同时, 也为教师 在探索创新型人才培养模式的教学和科研改革方面提供 了可管可控的操作环境, 确定了一整套基于网络融合的实 训项目, 并进行了教学方式的改革和探索, 取得了良好的 教学效果。此实训平台的建立从项目方案的设计、实施、 验收到运行得到了同行专家的一致认可和高度评价, 目前 在各大高校实验室建设方面已起到示范和指导作用。在此, 还需要不断深入实践改革, 不断完善实训平台的教学体系, 为培养高质量的通信人才而不断努力。

\section{致谢}

本文受北京市教委 “青年英才计划” 项目资助。项目 编号: YETP1957。

\section{参考文献}

[1] 刘小莉等. 三网融合实验教学平台建设与实践 $[J]$. 实验室 研究与探索, 2011, 30(12): 141-143。

[2] 周训斌. 三网融合技术及实训平台建设的研究与实践 $[J]$. 长沙通信职业技术学院学报, 2011，10(2)：1-4。

[3] 刘小莉等. 融合网络下的广电工程实验实训平台建设与实 践 $[J]$. 实验技术与管理, 2013, 30 (3)：184-186。

[4] 曾爱华等. IPTV 系统架构及主要技术 [J]. 通信技术, 2010, (3)。

[5] 谢晓元. IPTV接入网解决方案研究 $[J]$. 江苏通信技术, 2006, 22 (6) : 41-45。

[6] 苏莹等. 广播电视实验教学示范中心的建设与实践 $[J]$. 湖 北经济学院学报：人文社科版, 2009, 6 (3) : 155-156。

[7] 刘小莉等. VoIP实训平台构建 $[J]$. 实验科学与技术, 2015, $13(6)$ : 134-137。

［8］郝洁. 基于 “三网融合” 实训平台中VOIP通信的设计与实现 [D]. 成都：电子科技大学，2013：20。

[9] 罗晓东. 基于三网融合通信应用实训项目的研究 [D]. 成都: 电子科技大学，2013：20。

[10］宋真君等. VOIP及融合通信项目实验指导书 $[M]$. 北京: 电子 工业出版社，2007。 